\title{
Fronteiras e o equilíbrio trabalho-lar: um estudo com profissionais de segurança pública
}

\author{
Alexandre dos Santos Cerqueira \\ Universidade Federal do Espírito Santo (UFES) \\ Bruno Felix \\ FUCAPE Business School \\ Sabrina Zanotti Galon \\ FUCAPE Business School \\ Ariana Marchezi de Souza \\ Universidade Federal do Espírito Santo (UFES)
}

Há um cenário propício para a ocorrência de conflitos entre as dimensões de lar e trabalho na vida de profissionais de diferentes áreas. A pesquisa alicerçou-se na Teoria das Táticas de Manejo de Fronteiras, com o objetivo de investigar como os profissionais do setor de segurança pública negociam as fronteiras entre trabalho e lar. A escolha por esse grupo deveu-se às particularidades relacionadas aos trabalhos com riscos e às demandas súbitas. O método utilizado foi o qualitativo, com a realização de entrevistas em profundidade por meio de roteiro semiestruturado. A amostra foi composta por 20 bombeiros militares (BM) e 8 policiais militares (PM), e, como procedimento de análise dos dados, optou-se pela análise de conteúdo. A pesquisa revelou o uso das táticas de manejo de fronteiras em todas as quatro dimensões (comportamental, temporal, física e comunicativa).

Palavras-chave: servidor público, direito à privacidade, segurança pública

[Artigo recebido em 14 de fevereiro de 2016. Aprovado em 20 de fevereiro de 2017.] 


\section{Fronteras y trabajo-hogar balance: un estudio de profesionales de la seguridad pública}

Hay un escenario favorable para la aparición de conflictos entre las dimensiones hogar y trabajo en la vida de los profesionales de las diferentes áreas. La investigación tiene sus fundamentos en la teoría de las tácticas de gestión de fronteras. El objetivo fue investigar como los profesionales del sector de la seguridad pública negocian los límites entre el trabajo y el hogar. El método utilizado fue cualitativo, con la realización de entrevistas en profundidad con lo guión semiestructurado. La muestra estaba compuesta por 20 bomberos (BM) y 8 de la policía militar (PM), y se eligió la análisis de contenido cómo el procedimiento de análisis de datos. La elección de este grupo se debió a las características específicas asociadas a los riesgos de trabajo y demandas repentinas. La búsqueda reveló el uso de tácticas de gestión de fronteras en las cuatro dimensiones (conductual, temporal, física y comunicativa).

Palabras clave: servidor público, derecho a la privacidad, seguridad pública

\section{Borders and work-home balance: a study of public security professionals}

There is a favorable scenario for the occurrence of conflicts between home and work dimensions in the life of different areas of professionals. The research has its foundations on the theory of border management tactics. The objective was to investigate how professionals of public security sector negotiate the boundaries between work and home. The method used was qualitative, with in-depth interviews through a semi-structured script. The sample consisted of 20 military firemen (BM) and 8 military police (PM) and we opted for content analysis as a procedure of data analysis. The survey revealed the use of border management tactics in all four dimensions (behavioral, temporal, physical and communicative).

Keywords: public server, right to privacy, public security 


\section{Introdução}

Atualmente nota-se um cenário propício para a ocorrência de conflitos entre as dimensões do lar e do trabalho na vida de profissionais de diferentes áreas de atuação. A tendência de crescimento da participação feminina no mercado de trabalho, suas consequentes implicações para as divisões de responsabilidades no lar e a popularização de tecnologias que possibilitam que demandas do lar e do trabalho sejam atendidas nos mesmos espaços e momentos têm tornado complexa a tarefa de administrar os domínios pessoal e profissional da vida. Tal configuração tende a produzir conflitos indesejáveis tanto para os indivíduos quanto para as organizações (ARAUjo; TURETA; ARAUjo, 2015). O termo conflito trabalho-família costuma estar associado a resultados sociais indesejáveis, como estresse, rotatividade, absenteísmo, burnout, insatisfações com trabalho, família e vida e redução de produtividade (EDWARDS; ROTHBARD, 2000; KREINER, 2006; Parasuraman; Greenhaus, 2002; Rice; Frone; McFarlin, 1992; Allard; HaAs; HWANG, 2011; Ford; HeINEN; LANGKAMER, 2007). Por essa razão, o tema tem despertado crescente interesse em acadêmicos e profissionais do mercado.

A literatura sobre as relações entre trabalho e lar tem empregado predominantemente o método quantitativo e se encontra mais focada na identificação dos conflitos existentes entre o trabalho e o lar do que no possível equilíbrio entre as demandas dessas duas dimensões (CHANG; MCDONALD; BURTON, 2010). Embora essa perspectiva dominante tenha trazido contribuições relevantes para o estudo do conflito trabalho-lar, Nippert-Eng (1996) destacou a importância de se compreender qualitativamente como as pessoas negociam as fronteiras entre ambos os domínios, de forma a promover o equilíbrio entre eles. Assim, desloca-se o foco de pesquisa da descrição dos antecedentes e consequentes do conflito para as estratégias individuais de promoção do equilíbrio.

Essa perspectiva foi explorada em um estudo realizado com cientistas, que objetivava revelar táticas do cotidiano que esses profissionais usam para atingir um estado de harmonia nos relacionamentos profissionais e familiares (NIPPERTENG, 1996). Sob a mesma ótica, Kreiner, Hollensbe e Sheep (2009) analisaram o fenômeno com sacerdotes episcopais; Araujo , Tureta e Araujo (2015), com mãestrabalhadoras em meio de carreira; e Araujo, Rosa e Tureta (2012), com mulheres expatriadas no contexto de negócios.

Nesse contexto, verifica-se uma lacuna de pesquisa no que tange a melhor explorar as demandas dos domínios do trabalho e do lar no contexto de determinadas profissões ou ramos de atuação caracterizados como casos críticos de demanda por integração ou segmentação entre lar e trabalho. Assim, Kreiner, Hollensbe e Sheep (2009) sugerem que sejam realizados estudos qualitativos para investigar as 
táticas usadas por grupos com características distintas dos sujeitos de sua pesquisa. O ramo da segurança pública oferece um contexto propício para que as demandas de um domínio se manifestem no tempo e no espaço dedicados a priori a outro domínio, por exemplo, quando um profissional é chamado na madrugada para atender a uma emergência. No entanto, questões de segurança pessoal, familiar e de privacidade também podem criar um contexto que privilegie a separação entre os domínios de lar e trabalho, o que configura um interessante campo empírico para o entendimento dos mecanismos de busca pelo equilíbrio trabalho-lar.

Portanto, por meio de uma abordagem qualitativa, o objetivo deste estudo é investigar como profissionais do ramo da segurança pública negociam as fronteiras entre trabalho e lar. A escolha do grupo social deveu-se às seguintes razões: (1) os profissionais executam simultaneamente trabalhos administrativos e operacionais; (2) suas demandas são programadas ou súbitas, com chamados de trabalho a qualquer momento; (3) alguns trabalhos emergenciais são arriscados, o que gera preocupações na família; e (4) as famílias desses profissionais tendem a enfrentar problemas de adaptação aos conflitos entre o trabalho e o lar, oriundos das exigências das demandas de trabalho.

Para tanto, a pesquisa encontra-se alicerçada em termos teóricos na Teoria das Fronteiras, dedicada a estudar como as pessoas criam e sustentam suas fronteiras de modo a organizar o ambiente em que estão inseridas (ASHFORTH; KREINER; FugATE, 2000), e na Teoria das Táticas de Manejo de Fronteiras, na qual as pessoas constroem e manejam socialmente fronteiras físicas e não físicas entre os domínios de trabalho e lar (KREINER; Hollensbe; SHeEP, 2009).

Esta pesquisa poderá contribuir para a literatura de gestão de pessoas no ramo da segurança pública, na medida em que ampliará o foco de pesquisa para a resolução dos problemas ocasionados pelo conflito entre trabalho e lar. Quanto à literatura acerca do equilíbrio trabalho-lar, o estudo acrescentará informações sobre as especificidades de um grupo social com forte tendência a conflitos também recorrentes em outras profissões. Em termos práticos, destaca-se a possibilidade de oferecer um conjunto de táticas que podem favorecer o alcance do equilíbrio trabalho-lar para os profissionais de segurança pública, além da replicação das melhores práticas relacionadas à solução dos conflitos por profissionais de setores semelhantes.

\section{Referencial teórico}

\section{Interface e fronteira trabalho-lar}

Embora existam múltiplas lentes teóricas para o estudo da interface entre trabalho e lar, nota-se, nesse campo do conhecimento, o crescimento de uma corrente que 
estrutura a interface trabalho-lar como uma fronteira socialmente construída entre esses dois domínios (Kreiner; Hollensbe; Sheep, 2009). Tal abordagem identifica táticas que os indivíduos podem utilizar a partir do controle que possuem sobre as experiências, interpretações e visões de mundo (CLARK, 2000; NIPPERT-ENG, 1996). Apesar dessa vertente de construção social tratar o indivíduo como parte ativa na construção de fronteiras, outras abordagens apresentam o indivíduo como um agente passivo das condições ambientais. Portanto, a abordagem da construção social pode ser vista como uma lente útil para o estudo da Teoria das Fronteiras nas relações trabalho-lar.

A Teoria das Fronteiras foi utilizada por Nippert-Eng (1996) com o intuito de compreender a negociação da interface entre o trabalho e o lar e esclarecer como as pessoas criam, mantêm e mudam as fronteiras para o melhor convívio com o mundo à sua volta (ASHFORTH; KREINER; FUGATE, 2000). De forma geral, as fronteiras delimitam o perímetro dos domínios referentes à função, ao país, ao lar e ao local de trabalho, e são construídas ao longo de um continnum, variando conforme a flexibilidade e a permeabilidade (KREINER; HollensBe; SHEEP, 2009).

A flexibilidade é temporal e está relacionada à capacidade do indivíduo de atender as demandas de um domínio por meio da utilização do tempo disponível de outro domínio (SUNDARAMURTHY; KREINER, 2008), por exemplo, quando uma pessoa realiza pagamentos pessoais no trabalho através do computador da organização. $A$ permeabilidade, por sua vez, é espacial e está relacionada à integração do papel de um domínio em outro domínio (AShForth; KREINER; FugATE, 2000), como, por exemplo, quando um indivíduo convida clientes para um almoço em sua residência para tratar de assuntos relacionados ao trabalho. Vale ressaltar que as fronteiras flexíveis e permeáveis são finas (fracas), abertas a influências e levam à integração de papéis. Por outro lado, as fronteiras inflexíveis e impermeáveis são espessas (fortes), o que dificulta que os valores ou crenças dos domínios sejam influenciados e induz a uma segmentação de papéis (KREINER; HolLENSBE; SHEEP, 2009).

Nippert-Eng (1996) identificou que alguns indivíduos tendem a segmentar os domínios do lar e do trabalho, designando as atividades e as maneiras de agir em cada contexto, enquanto outros preferem integrar o lar e o trabalho sem distinções, desempenhando atividades de ambos os domínios, independente do local e do tempo de realização. Sendo assim, Kreiner, Hollensbe e Sheep (2009) sugerem que a teoria de ajuste ou congruência indivíduo-ambiente configura um modelo de trabalho para o entendimento dos conflitos de fronteiras.

O estudo das congruências e incongruências entre o entendimento dos indivíduos sobre o ambiente e as preferências individuais com relação à integração ou segmentação permite compreender melhor os conflitos entre os domínios trabalho e lar. De acordo com a teoria de ajuste indivíduo-ambiente, as congruências entre o 
indivíduo e as variáveis situacionais, em suma, levam a resultados positivos, como satisfação, ao passo que as incongruências produzem resultados negativos, como a tensão e o conflito (KULKA, 1979).

Demandas conflitantes e prazos apertados criam tensões entre os empregados, o que reduz a capacidade de domínio das tarefas pessoais, gerando sentimentos de insatisfação com o equilíbrio lar-trabalho (BEHAM; DROBNIC, 2010). Kreiner, Hollensbe e Sheep (2009) sugerem que as preferências individuais e as influências ambientais causam congruências e incongruências de fronteiras nesses domínios em cinco dimensões: membros das famílias, superiores, subordinados, clientes e ocupação. Os mesmos autores apontaram que as incongruências têm por consequência as violações e os conflitos.

As violações de fronteiras referem-se aos momentos em que uma fronteira não é tratada de acordo com a preferência do indivíduo; tais momentos são distinguidos entre violações de intrusão e de distância (KATHERINE, 1991; KREINER; HOLLENSBE; SHEEP, 2006), sendo as primeiras relacionadas ao rompimento de uma das fronteiras e as segundas resultantes da criação de uma distância considerável entre os domínios. Sob esse prisma, a violação de fronteira é definida como uma percepção individual, na qual um comportamento, um episódio ou um evento rompe ou afasta uma importante faceta da fronteira trabalho-lar desejada (KREINER; HollensBe; SHEeP, 2009). Logo, a intrusão acontece quando um indivíduo deseja a segmentação, porém a violação força uma integração (HILL; DARLING; RAIMONDI, 2003), por exemplo, quando familiares contatam o indivíduo no horário de trabalho para a resolução de problemas pessoais. Já a violação de distância ocorre quando é desejada a integração, mas a segmentação é forçada (KATHERINE, 1991), por exemplo, quando o indivíduo deseja ser acionado pelo superior no horário de folga quando surgir uma eventual demanda de trabalho.

É importante ressaltar que as violações de fronteiras estão relacionadas aos conflitos trabalho-lar e não devem ser tratadas independentemente. Violar fronteiras pode gerar conflito entre os domínios, devido à incompatibilidade de expectativas quanto aos papéis dos indivíduos (KREINER; HollensBe; SHEEP, 2009).

Ao se considerarem os efeitos das incongruências dessas fronteiras, os indivíduos desenvolvem táticas para amenizar ou, até mesmo, neutralizar efeitos negativos como a tensão, a insatisfação com o trabalho e os conflitos citados anteriormente.

\section{Táticas de manejo de fronteiras}

Diante do amplo campo de estudo da Teoria das Fronteiras, Nippert-Eng (1996) apresentou o conceito de manejo de fronteiras para descrever de que forma as pessoas se esforçam para construir, desconstruir e manter a fronteira entre casa e trabalho. Desse modo, foram identificadas estratégias de integração e segmentação 
utilizadas para negociar as fronteiras entre os dois domínios, por exemplo, enquanto os segmentadores usam acessórios exclusivos como carteiras, calendários e molhos de chaves em cada domínio, os integradores usam um exemplar para cada um desses objetos nos dois ambientes.

Kreiner, Hollensbe e Sheep (2009) desenvolveram uma teoria sobre as táticas de manejo de fronteiras baseados no estudo de Nippert-Eng (1996) e também na proposta de McDermid (2005) de compreender como os indivíduos podem responder positivamente a incongruências de fronteiras entre trabalho e lar. Segundo tal teoria, os indivíduos influenciados pelo ambiente em que estão inseridos podem apresentar preferências, por exemplo, pela segmentação dos domínios (ROTHBARD; PHILLIPS; DUMAS, 2005), gerando incongruências (violações e conflito) que podem ser amenizadas via táticas de manejo - decisões relativas à dinâmica trabalho-lar tomadas para a renegociação de fronteiras (POWELL; GREENHAUS, 2010).

Kreiner, Hollensbe e Sheep (2009) classificaram as táticas de manejo em quatro categorias: comportamentais, temporais, físicas e comunicativas. Dentre as táticas comportamentais, destaca-se o uso de outras pessoas (utilizar a disponibilidade e as habilidades de outrem), o uso da tecnologia (empregar recursos como bina, e-mail e secretária eletrônica), o uso de triagens (priorizar demandas urgentes e importantes) e a permissão de permeabilidade diferenciada (escolher o tipo de fronteira para aspectos específicos). As táticas temporais contemplam ações de controlar o tempo de trabalho (criar créditos de tempo em domínio para ser compensado no futuro) e encontrar trégua (tornar-se temporariamente indisponível para trabalho, lar ou ambos). Já as táticas físicas relacionam-se à adaptação de fronteiras físicas (criar ou eliminar barreiras ou fronteiras entre lar e trabalho), à manipulação do espaço físico (criar uma "terra de ninguém" entre trabalho e lar) e ao gerenciamento de artefatos físicos (usar itens tangíveis como chaves, calendários ou carteira para separar ou misturar os dois domínios). Por último, as táticas comunicativas envolvem ações de estabelecer expectativas (apresentar antecipadamente a envolvidos as preferências quanto a fronteiras) e confrontar os violadores (informando as fronteiras trabalholar ao violador durante ou após a violação).

Vale ressaltar que tais táticas não são taxativas, podendo ser aplicadas simultaneamente de modo sinérgico para o alcance do equilíbrio trabalho-lar.

\section{Profissionais de segurança pública e equilíbrio trabalho-lar}

$\mathrm{Na}$ última década, o desempenho do serviço público atraiu a atenção de pesquisadores (BREWER; HUPE, 2007), e especificamente o tema equilíbrio trabalholar permanece em voga. Como exemplo, pode-se citar que a administração pública no Reino Unido tem sido ativa no sentido de progredir com políticas e práticas nesse âmbito (MAXWELL; McDougaLL, 2004). 
Os benefícios organizacionais oriundos do equilíbrio trabalho-lar estão relacionados à retenção de profissionais, qualidade dos serviços (LASCH, 1999) e redução do turnover e absence (GlynN; Steinberg; McCARTNEY, 2002). Por outro lado, dada a melhor capacidade de lidar com os compromissos profissionais e pessoais, os benefícios individuais vão além da minimização dos conflitos de papéis (CARLSON; KACMAR; STEPINA, 1995), do aumento do tempo com dependentes e de um staff mais feliz (HOGARTH; HASLUCK; PIERRE, 2001). Adicionalmente, pode-se dizer que os indivíduos experimentam aumentos de produtividade, motivação e comprometimento como resultado do maior equilíbrio trabalho-lar (MAXWELL; MCDOUGALL, 2004).

É importante destacar que os profissionais de segurança pública compõem a administração pública direta e estão envolvidos no cumprimento das missões constitucionais relacionadas ao policiamento, investigação e atendimento a emergências e desastres. No âmbito federal, o setor de segurança pública é composto pela polícia federal e rodoviária federal, e, na esfera estadual, as polícias militares, civis e corpos de bombeiros. Em geral, esses profissionais atuam em sistema de escalas e podem ser acionados em momentos de folga, caso haja alguma demanda eventual.

Embora diversas organizações de segurança pública adotem opções de flexibilidade no trabalho que até convergem com as preferências individuais por integração ou segmentação, é fundamental a participação ativa do indivíduo na busca do equilíbrio trabalho-lar via táticas de manejo (MAINIERO; SULLIVAN, 2005).

\section{Método de pesquisa}

Conforme o objetivo da pesquisa de investigar como profissionais do ramo da segurança pública negociam as fronteiras entre trabalho e lar, foi utilizado neste estudo o método de pesquisa qualitativo. Segundo Godoy (1995), quando o pesquisador coloca-se no papel do pesquisado, pode-se absorver melhor os acontecimentos que se deseja observar. Devido à natureza da pesquisa, os eventos estudados não foram analisados estatisticamente; a obtenção dos dados foi viabilizada por meio da interação direta entre o pesquisador e os sujeitos da pesquisa, com o intuito de entender o fenômeno a partir dos próprios participantes.

A população da pesquisa compôs-se de funcionários da área de segurança pública, dada a escassez de pesquisas nesse setor (BOYNE, 2004). Foram escolhidos o Corpo de Bombeiros Militar do Espírito Santo (CBMES) e a Polícia Militar do Estado do Espírito Santo (PMES) como campo de estudo, em função da relevância dessas organizações para a sociedade e da representatividade no setor de segurança pública, foco do estudo. A amostra, não probabilística de conveniência, foi composta por 20 bombeiros militares (BM) e oito policiais militares (PM).

É importante esclarecer que a escolha por pautar a pesquisa no modelo teórico de Kreiner, Hollensbe e Sheep (2009) é derivada das sugestões dos próprios autores 
de futuramente replicar o modelo em grupos distintos, visto que o estudo original restringiu-se a sacerdotes episcopais. Sendo assim, a seleção da amostra considerou a escolha de indivíduos que possuíssem distintas características, tanto em termos de turno (administrativo ou escalas), quanto de perfil pessoal (gênero, idade, nível hierárquico, estado civil, tempo de profissão etc.). O perfil diferenciado dos participantes permite que haja a presença de múltiplas perspectivas do mesmo fenômeno em questão, o que contribui para a redução dos vieses em estudos qualitativos (EISENHARDT; GRAEBNER, 2007). Na Tabela 1 é apresentado o perfil dos participantes da pesquisa.

Tabela 1 - Perfil dos participantes da pesquisa

\begin{tabular}{|c|c|c|c|c|}
\hline & Frequência & $\%$ & Média & Desvio padrão \\
\hline \multicolumn{5}{|l|}{ Idade } \\
\hline Até 25 anos & 3 & $11 \%$ & & \\
\hline Entre 26 e 31 & 3 & $11 \%$ & & \\
\hline Entre 32 e 37 & 3 & $11 \%$ & & \\
\hline Entre 38 e 43 & 13 & $46 \%$ & & \\
\hline Entre 44 e 49 & 6 & $21 \%$ & & \\
\hline Tempo de serviço & & & 16 & 8,35 \\
\hline Até 5 anos & 7 & $25 \%$ & & \\
\hline Entre 6 e 11 & 1 & $4 \%$ & & \\
\hline Entre 12 e 17 & 2 & $7 \%$ & & \\
\hline Entre 18 e 23 & 14 & $50 \%$ & & \\
\hline Entre 24 e 29 & 4 & $14 \%$ & & \\
\hline \multicolumn{5}{|l|}{ Gênero } \\
\hline Masculino & 21 & $75 \%$ & & \\
\hline Feminino & 7 & $25 \%$ & & \\
\hline \multicolumn{5}{|l|}{ Nível hierárquico } \\
\hline Soldado & 6 & $21 \%$ & & \\
\hline Cabo & 1 & $4 \%$ & & \\
\hline Sargento & 6 & $21 \%$ & & \\
\hline Subtenente & 3 & $11 \%$ & & \\
\hline Tenente & 2 & $7 \%$ & & \\
\hline Capitão & 3 & $11 \%$ & & \\
\hline Major & 6 & $21 \%$ & & \\
\hline Ten Coronel & 1 & $4 \%$ & & \\
\hline \multicolumn{5}{|l|}{ Turno } \\
\hline Administrativo & 20 & $71 \%$ & & \\
\hline Escala & 8 & $29 \%$ & & \\
\hline \multicolumn{5}{|l|}{ Estado civil } \\
\hline Solteiro & 3 & $11 \%$ & & \\
\hline Casado & 25 & $89 \%$ & & \\
\hline \multicolumn{5}{|l|}{ Filhos? } \\
\hline Sim & 22 & $79 \%$ & & \\
\hline Não & 6 & $21 \%$ & & \\
\hline
\end{tabular}

Fonte: Elaboração própria a partir de dados da pesquisa. 
Conforme a Tabela 1, os participantes são predominantemente do gênero masculino, casados e com filhos, têm em média 38 anos e trabalham há 16 anos. Quanto ao nível hierárquico, a maioria atua nas posições de soldado, sargento e major.

Para a coleta dos dados, realizaram-se entrevistas em profundidade, individuais e presenciais, com roteiro semiestruturado. O número de entrevistados é resultante da técnica de saturação ou redundância teórica (GLASER; STRAUSS, 1968), ou seja, na medida em que casos similares são detectados, o investigador adquire confiança empírica de que não serão encontrados dados adicionais que possam contribuir com o desenvolvimento da pesquisa. Sendo assim, foram feitas 28 entrevistas, com duração média de 30 minutos.

O roteiro semiestruturado foi subdivido nos seguintes assuntos: (1) descrição do perfil do entrevistado para a caracterização da amostra; (2) desafios relacionados ao equilíbrio trabalho-lar com intuito de detectar a flexibilidade e permeabilidade propostas pelo referencial teórico; (3) preferências individuais e/ou organizacionais por segmentação ou integração, a fim de revelar as táticas utilizadas pelos profissionais; e (5) táticas de manejo de fronteiras, para validar a ocorrência das categorias propostas por Kreiner, Hollensbe e Sheep (2009). Destaca-se que, no decorrer das entrevistas, o pesquisador pôde criar novas perguntas de forma improvisada, conforme abertura e interação com os participantes, o que permitiu que o tema de pesquisa fosse explorado em maior profundidade.

Após a transcrição e a codificação das entrevistas, utilizou-se a análise de conteúdo proposta por Bardin (2004) e Yin (2003) para analisar os dados por meio da lógica de replicação. Essa técnica adequa-se aos estudos que buscam referenciar pesquisas que utilizam teorias fundamentadas como modelos teóricos, sendo viavelmente aplicável ao presente estudo. A escolha por essa técnica deveu-se também à possibilidade de replicação da teoria de Kreiner, Hollensbe e Sheep (2009) em contextos diferenciados, com prováveis contribuições à teoria de base. Dessa forma, na etapa de análise dos dados, a codificação baseou-se na identificação do uso das táticas de manejo de fronteiras (comportamentais, físicas, temporais e comunicativas), bem como na utilização de possíveis novas táticas.

\section{Análise e discussão dos resultados}

Esta pesquisa identificou táticas utilizadas por profissionais de segurança pública para negociar as fronteiras entre o trabalho e o lar. A análise dos resultados revelou o uso de todas as categorias de táticas de manejo de fronteiras propostas por Kreiner, Hollensbe e Sheep (2009), conforme exposto no Quadro 1. 
Quadro 1 - Táticas de manejo de fronteiras utilizadas no setor de segurança pública

\begin{tabular}{|c|c|c|}
\hline Nome & Respondentes & Descrição \\
\hline $\begin{array}{l}\text { Táticas comportamentais } \\
\text { Uso de outras pessoas }\end{array}$ & $50 \%$ & $\begin{array}{l}\text { Utilização de outras pessoas } \\
\text { para facilitar o gerenciamento } \\
\text { das fronteiras entre } \\
\text { trabalho-lar. }\end{array}$ \\
\hline Uso de tecnologia & $100 \%$ & $\begin{array}{l}\text { Emprego de recursos como } \\
\text { celulares e e-mail. }\end{array}$ \\
\hline $\begin{array}{l}\text { Definição de prioridades com } \\
\text { antecedência }\end{array}$ & $75 \%$ & $\begin{array}{l}\text { Planejamento das prioridades } \\
\text { de forma antecipada e } \\
\text { priorização das demandas } \\
\text { urgentes e importantes. }\end{array}$ \\
\hline $\begin{array}{l}\text { Permissão de permeabilidade } \\
\text { diferenciada }\end{array}$ & $50 \%$ & $\begin{array}{l}\text { Alteração do tipo de fronteira } \\
\text { para aspectos específicos. }\end{array}$ \\
\hline $\begin{array}{l}\text { Táticas temporais } \\
\text { Controle do tempo de trabalho }\end{array}$ & $50 \%$ & $\begin{array}{l}\text { Criação créditos de tempo para } \\
\text { serem compensado no futuro. }\end{array}$ \\
\hline $\begin{array}{l}\text { Táticas físicas } \\
\text { Manipulação de fronteiras } \\
\text { físicas }\end{array}$ & $55 \%$ & $\begin{array}{l}\text { Estabelecimento, criação ou } \\
\text { eliminação de barreiras ou } \\
\text { fronteiras entre trabalho e lar. }\end{array}$ \\
\hline $\begin{array}{l}\text { Gerenciamento de artefatos } \\
\text { físicos }\end{array}$ & $100 \%$ & $\begin{array}{l}\text { Uso de itens tangíveis para } \\
\text { separar ou misturar os dois } \\
\text { domínios. }\end{array}$ \\
\hline $\begin{array}{l}\text { Táticas comunicativas } \\
\text { Estabelecer expectativas }\end{array}$ & $55 \%$ & $\begin{array}{l}\text { Comunicação } \\
\text { antecipadamente aos } \\
\text { envolvidos das preferências } \\
\text { quanto às fronteiras entre } \\
\text { trabalho e lar. }\end{array}$ \\
\hline Confrontar os violadores & $10 \%$ & $\begin{array}{l}\text { Informação das fronteiras } \\
\text { trabalho-lar ao violador } \\
\text { durante ou após a violação }\end{array}$ \\
\hline
\end{tabular}

Fonte: Elaboração própria a partir de dados da pesquisa.

De acordo com o Quadro 1, todos os profissionais relataram utilizar recursos tecnológicos como celulares e e-mail, bem como artefatos físicos para separar ou misturar os domínios lar e trabalho. Ademais, grande parte dos entrevistados 
revelou que define prioridades com antecedência, manipula fronteiras físicas e estabelece expectativas por meio da comunicação antecipada aos envolvidos, dada a especificidade de conviver na iminência de emergências. Embora todas as táticas apresentadas pelo referencial teórico tenham sido detectadas, não foi diagnosticada a utilização de novas categorias ou tipos diferenciados de táticas.

Nos tópicos seguintes serão apresentados trechos das entrevistas, o que permitirá visualizar de forma clara de que maneira as táticas são empregadas e quais são as mais utilizadas no contexto estudado.

\section{Táticas comportamentais}

Dado que os profissionais do Corpo de Bombeiros Militar e Polícia Militar seguem uma escala mensal de atendimento a demandas habituais e/ou eventuais, uma das táticas de manejo mais utilizadas para alcançar o equilíbrio entre os dois domínios é a comportamental. Neste estudo, foram encontrados quatro tipos de táticas comportamentais: uso de outras pessoas, uso de tecnologia, definição de prioridades com antecedência e permissão de permeabilidade diferenciada.

Uso de outras pessoas

Refere-se ao uso da disponibilidade e das habilidades de outras pessoas (KREINER; HOLLENSBE; SHEEP, 2009), por exemplo, quando familiares são acionados com a chegada dos filhos, dado o aumento das demandas do lar. Em geral, as pessoas que se utilizam dessa estratégia contam com colegas de trabalho de semelhante expertise para auxiliar na demanda do serviço por meio da troca de escalas.

Os entrevistados que já utilizaram essa tática definiram que o apoio dessas pessoas ameniza os conflitos entre os domínios e contribui para equilibrar o desafio de organizar e otimizar o tempo. As seguintes citações confirmam esse ponto de vista:

E 13: Um ajuda o outro, a gente tem essa flexibilidade de trocar de escala. Se tem uma prioridade, eu seguro sua escala e depois você tira a minha em outro momento.

E 10: Sempre tenho ajuda da minha família. Por exemplo, agora mesmo que minha esposa está para ter filho, que antecede o parto, meu sogro e minha sogra estão lá cuidando dela.

E 6: Quando não há como cumprir a missão, tento colocar outro no lugar que tenha a mesmo expertise.

Pode-se notar que a troca de escalas é utilizada por meio de um comportamento amigável entre os colegas de trabalho, o que se traduz numa parceria com que se pode contar nas necessidades e demandas futuras. Por outro lado, o apoio dos familiares 
é fundamental para equilibrar os conflitos e fornecer um sentimento de segurança que favoreça o cumprimento das atividades profissionais sem interferências do lar e, por conseguinte, sem prejuízos à produtividade do funcionário.

Os resultados acima apresentados corroboram os estudos de Carlson, Kacmar e Stepina (1995) e Hogarth, Hasluck e Pierre (2001) no que tange aos inúmeros benefícios individuais alcançados com a utilização dessa tática, entre eles: melhor capacidade de lidar com os compromissos profissionais e pessoais, redução de conflitos no lar e aumento do bem-estar do indivíduo.

Uso de tecnologia

O usufruto de ferramentas tecnológicas como telefones celulares e correio eletrônico foi sinalizado como uma tática crucial de manejo de fronteiras. Todos os entrevistados destacaram a tecnologia como aliada na mitigação dos conflitos trabalho-lar, o que pode ser observado na fala dos entrevistados E 23 e E27:

E 23: [...] levar rádio para casa, fazer sua casa uma extensão do seu trabalho, um escritório, agora tem a onda de e-mails eletrônicos, torpedos, então se a pessoa não se vigiar ela pode ter prejuízos familiares.

E 27: As novas tecnologias estão aí... está recebendo e-mail... está recebendo ligação... o celular chama o tempo todo, então você tenta minimizar, mitigar essa situação toda, mas dizer que chega em casa e está totalmente desligado ou vice-versa... você no trabalho está em virtude das tecnologias.

Os trechos acima convergem com os achados de Kreiner, Hollensbe e Sheep (2009) no tocante à condição favorável que os dispositivos tecnológicos proporcionam na resolução dos conflitos trabalho-lar.

\section{Definição de prioridades com antecedência}

Grande parte dos entrevistados relatou que planejam prioridades antecipadamente e priorizam demandas urgentes e importantes, conforme apontado nos trechos abaixo:

E 1: É muito mais fácil conciliar o trabalho quando não se tem filhos e cônjuge. Mesmo assim, sempre marco meus compromissos com uma segunda opção de suporte.

E 12: Eu sou recém-casado, mas no momento eu tenho tido mais dificuldade em conciliar a vida tripla, eu trabalho, sou chefe de família e estudo. Para equilibrar isso, eu tenho que planejar bem o meu tempo.

E 3: "Minha vida é muito bem planejada, então não tem muito problema. Quando eu saio de casa, eu já deixo tudo bem organizado, tenho pessoas que me ajudam". 
Embora utilizada de forma evidente por funcionários que têm filhos, notou-se que essa tática comportamental é praticada por todos os perfis de entrevistados, especialmente por aqueles que conciliam a tríade trabalho-estudo-lar. Isso reitera os achados de Carlson, Kacmar e Stephina (1995) no que tange à minimização do conflito lar-trabalho frente à capacidade de organizar antecipadamente os compromissos pessoais e profissionais.

\section{Permissão de permeabilidade diferenciada}

A tática de alterar o tipo de fronteira para aspectos específicos é notável nos trechos abaixo:

E 2: Trabalho é trabalho, família é família. Apesar de que, igual ontem, ela teve febre porque está nascendo um dentinho, foi meio difícil separar porque eu tive que pedir pro meu chefe: "Olha posso sair mais cedo um pouquinho?".

E 4: Eu prefiro segmentar, mas às vezes é preciso resolver assuntos pessoais e familiares no trabalho: filho na escolha, filho levado demais.

Assim, há permissão a determinadas intrusões no ambiente de trabalho para resolver alguma demanda imprevista do lar. Principalmente aqueles funcionários incumbidos de serviços administrativos declararam que a instituição é flexível perante as demandas familiares, o que contribui para a prática da permeabilidade diferenciada no ambiente organizacional:

E 3: Quando tem uma apresentação de karatê na escola de seu filho no horário do expediente, você, como pai, você tem que participar desses momentos, então você vai chegar e vai falar o que você tem e dentro do horário você vai sair e voltar. Aqui é flexível de se trabalhar.

A situação inversa também ocorre com os profissionais de segurança pública, os quais são conscientes de que o trabalho pode invadir as fronteiras domésticas a qualquer momento, devido à especificidade da atividade. Os trechos a seguir evidenciam a permeabilidade diferenciada também no domínio lar:

E 5: Devido à cultura do trabalho do bombeiro, nosso trabalho não se resume ao horário do expediente, eu sou bombeiro a qualquer tempo.

E 13: O fato de me ligar no horário de folga já é um desrespeito de fronteira. Mas no meio militar não tem jeito, você já entra sabendo que vai ter esse tipo de coisa.

Nota-se que a abdicação ao domínio lar durante os chamados de emergência é um pré-requisito para a entrada nesse setor de atuação profissional, passível de demandas imprevistas e urgentes. Esse cenário de permeabilidade diferenciada 
definida a priori pressupõe, assim como Mainiero e Sullivan (2005) notaram, a participação ativa do profissional na busca incessante pelo equilíbrio trabalho-lar.

\section{Táticas temporais}

As táticas temporais são utilizadas para maximizar a eficácia do uso do tempo, um dos principais desafios frente à díade trabalho-lar (KREINER; HollensBe; SHEEP, 2009). Neste estudo foi diagnosticada especificamente a tática de controle do tempo de trabalho.

\section{Controle do tempo de trabalho}

Com o intuito de equilibrar a interface trabalho-lar, essa tática é operacionalizada por meio da criação de créditos de tempo no ambiente de trabalho, passíveis de compensação no futuro. As escalas de trabalho, características do meio de atuação profissional dos entrevistados, acabam por induzir essa prática, na qual é cedido o direito de gratificação pelo cumprimento antecipado de serviços e escalas.

E 4: Não sou de levar trabalho para casa, só em extrema necessidade, chego mais cedo no trabalho justamente para poder preservar esse momento.

E 8: Não vejo muita dificuldade de equilibrar. Meu trabalho eu procuro fazer aqui. Dá para ir levando. Procuro o tempo que tenho aqui para usar bem, para não ter que levar nada para casa.

Observa-se que esse controle do tempo, popularmente conhecido como banco de horas, é uma característica organizacional segmentadora que contribui para o equilíbrio entre os domínios. Em consonância com os estudos de Kreiner, Hollensbe e Sheep (2009) e Rothbard, Phillips e Dumas (2005), os resultados indicam que os indivíduos estimulados por políticas organizacionais podem optar pela segmentação dos domínios e munir-se de táticas que futuramente compensarão o aparente desequilíbrio entre trabalho e lar.

\section{Táticas físicas}

As táticas físicas estão relacionadas à manutenção individual das fronteiras, através da criação de espaços físicos e da definição prévia de papéis (KREINER; Hollensbe; SheEP, 2009). Tal tipo de tática foi detectado em duas formas: na manipulação de fronteiras físicas e no gerenciamento de artefatos físicos.

\section{Manipulação de fronteiras físicas}

Os dados revelaram que a maioria dos entrevistados alterou o perfil de integração por segmentação com o nascimento dos filhos, estabelecendo fronteiras anteriormente não delimitadas entre o lar e o trabalho. O aumento considerável da 
demanda do lar induziu à segmentação e ao delineamento dos papéis profissionais e familiares:

E 4: Antes da chegada dos meus filhos, eu trabalhava full time. Cansei de trabalhar até 3 a 4 horas da manhã para entregar projetos. Então, quando estou no trabalho, aí eu segmento e lá em casa também. Hoje eu sou segmentadora, estou em casa, são meus filhos e meu marido, penso neles o tempo todo.

E 5: Eu tenho uma criança de 2 anos e outra de 9 meses. Quando eu chego já tem a expectativa de eu ajudar, para minha esposa dar uma descansada. Então hoje é muito mais segmentado, mas já foi integrado.

E 7: Eu sempre evitei compartilhar situações do serviço. Já vi gente pirar porque não conseguem separar essas coisas. Quando estou em casa, eu esqueço isso aqui, só se a demanda surgir, o que é eventual.

Os benefícios oriundos da substituição de uma condição integradora por uma rotina segmentada são semelhantes aos propostos por Hogarth, Hasluck e Pierre (2001) no tocante ao aumento do tempo com dependentes e à melhoria do bemestar do indivíduo.

\section{Gerenciamento de artefatos físicos}

Dado o militarismo característico das organizações pesquisadas, a utilização de símbolos militares e uniformes é evidente na rotina dos entrevistados, em sua maioria orientados para a segmentação trabalho-lar. Os relatos abaixo exemplificam como a utilização do uniforme pode segmentar os dois domínios:

E 9: A minha farda fica no quartel, nós temos armário aqui, então eu troco de roupa no quartel. Não gosto de misturar as coisas e pode ser que eu depare com um acidente e se estiver fardada terei de atender e isso é perigoso porque não tenho equipamentos no meu carro.

E 26: Na verdade eu tento separar. Fardado, o único lugar que eu vou é de casa para o trabalho. Esporadicamente na hora do almoço vou almoçar fardado, mas em outros lugares eu não vou fardado além desses lugares de trabalho.

Quanto a outros artefatos físicos, como porta-retratos, os entrevistados relataram não possuir fotos pessoais no ambiente de trabalho e vice-versa, justamente para não integrar os domínios.

Os resultados encontrados complementam a proposta de McDermid (2005) de identificar respostas positivas a incongruências de fronteiras entre trabalho e lar, posto que essa tática de segregação por meio de artefatos físicos configurouse numa das principais estratégias utilizadas para equilibrar a atenção e o tempo destinado à família e à corporação. 


\section{Táticas comunicativas}

As táticas comunicativas consideram a ação de comunicar as expectativas individuais e organizacionais quanto à integração ou a segmentação das fronteiras entre o trabalho e o lar e confrontar os violadores de tais fronteiras (KREINER; HOLLENSBE; SHEEP, 2009). Vale destacar que essa tática visa diminuir a violação das fronteiras e, consequentemente, a redução dos conflitos. As táticas comunicativas detectadas nesta pesquisa serão apresentadas a seguir.

\section{Estabelecer expectativas}

Devido à clara definição de regras das instituições militares, essa tática consiste na apresentação e na comunicação antecipada aos envolvidos, principalmente os familiares, das preferências quanto às fronteiras entre o trabalho e o lar.

E 21: Apesar de trabalhar no administrativo, nós, na minha cabeça e na cabeça da minha família... Eu deixo muito claro que se for pra ser chamado a qualquer momento, de manhã, de tarde, de noite e de madrugada... Meus filhos já cresceram nessa rotina, eu sempre explicava a situação e eles já compreendem.

E 7: Muito raramente resolvo assuntos pessoais no trabalho, não atendo telefone, peço para meu marido e meus pais não me ligarem, já coloco os meus horários para atender, que são os meus horários de almoço e quando eu puder ligar, a não ser que sejam questões de urgência. Eu peço à minha família esse comportamento.

Novamente é reforçado o resultado de Carlson, Kacmar e Stephina (1995) no que tange à redução do conflito entre os domínios quando se é capaz de organizar antecipadamente os compromissos pessoais e profissionais, por meio da definição prévia de expectativas.

\section{Controlar violadores}

Essa tática, exercida de forma reativa e corretiva, consiste na informação das fronteiras trabalho-lar ao violador durante ou após a violação. Apenas cerca de $10 \%$ dos entrevistados relataram o uso dessa tática, conforme indicado nos relatos abaixo:

E 23: [...] mas são poucos casos que procuram em casa, só quem realmente já me conhece tem um contato maior, mas é o que eu falei, eu entendo algumas situações devido ao stress que a pessoa é submetida, ansiedade.

E 28: Às vezes acontecem, mas eles entendem (família) quando você fala que está em uma reunião, e não pode falar agora, quando você deixa de atender o celular, eles sabem que você não pode atendê-los naquele momento e quando você atende eles também aceitam que você não tem muito tempo para falar. 
Isso robustece o estudo de Rothbard, Phillips e Dumas (2005) quanto à utilização de táticas que reforçam a preferência por uma condição segmentadora e, por conseguinte, corrigem um possível desequilíbrio ou violação entre trabalho e lar.

\section{Considerações finais}

Embora o estudo de Kreiner, Hollensbe e Sheep (2009) tenha trazido importantes contribuições para o entendimento do tema conflito/equilíbrio trabalho-lar, a aplicabilidade das táticas de manejo de fronteiras inerentes a atividades de sacerdotes episcopais poderia ser inadequada em outros grupos de profissionais. Sendo assim, definiu-se por replicar o estudo citado no grupo de profissionais do setor de segurança pública, mais especificamente os trabalhadores do Corpo de Bombeiro Militar do Estado do Espírito Santo e da Polícia Militar do Espírito Santo, o que direciona a pesquisa para uma perspectiva de construção social.

Apesar da possibilidade do diagnóstico de novas estratégias de manejo da interface trabalho-lar, todas as táticas utilizadas pelos bombeiros e policiais enquadraram-se nas quatro dimensões (comportamental, temporal, física e comunicativa) apresentadas por Kreiner, Hollensbe e Sheep (2009), o que reforça a relevância do referencial teórico utilizado neste estudo. Desse modo, a junção das similaridades entre as táticas encontradas neste estudo e aquelas detectadas por Nippert-Eng (1996) com os cientistas, por Kreiner, Hollensbe e Sheep (2009) com os sacerdotes episcopais, por Araujo, Tureta e Araujo (2015) com mães-trabalhadoras em meia carreira e por Araujo, Rosa e Tureta (2012) com mulheres expatriadas no contexto de negócios, revela algumas especificidades e limites no uso das táticas ao se considerar diferentes grupos de pessoas, mas também a aplicabilidade da teoria desenvolvida por esses autores ao considerar a diversidade de contextos de pesquisa.

O conflito trabalho-lar é um estado emocional, oriundo do acúmulo ou sucessão de eventos afetivos negativos ou positivos no cotidiano dos profissionais (WEISS; Cropanzano, 1996; ASHKANASY; HÄRTEl; DAUS, 2002; ASHKANASY et al., 2002). Sendo assim, as sucessivas e recorrentes violações de fronteiras podem agravar esse conflito, e, por outro lado, as táticas de manejo dessas fronteiras apresentam-se como uma alternativa para o alcance do estado de equilíbrio trabalho-lar (KREINER; Hollensbe; SheEP, 2009). Portanto, a perspectiva de construção social adotada neste estudo pode fornecer alternativas interessantes para o alcance do equilíbrio e a consequente redução do conflito, em função das particularidades vivenciadas por esses profissionais da segurança pública, que lidam frequentemente com situações de emergência, relacionadas à vida e ao patrimônio.

Sendo assim, devido ao conhecimento e à aceitação da natureza do serviço pelos funcionários da segurança pública e sua família, aos horários e tarefas 
antecipadamente registrados, à clara demarcação de regras e fronteiras entre trabalho-lar e ao uso das táticas de manejo de fronteiras em todas as suas dimensões, a tendência é que, mesmo que ocorram incongruências de fronteiras entre trabalho-lar, seja alcançado o equilíbrio trabalho-lar. Com exceção das demandas extraordinárias, devido a grandes desastres, situações de crise, emergências ou estados de calamidade, em que pode ocorrer a violação por intrusão por parte do trabalho (quando não se está escalado e a expectativa é de segmentação), podendo levar ao conflito trabalho-lar.

As descobertas relatadas neste estudo devem considerar as próprias limitações inerentes ao estudo qualitativo, ou seja, no momento da coleta dos dados, em entrevista individual, considera-se a possibilidade do fornecimento de respostas irreais pelos entrevistados, por se sentirem incomodados em exprimir suas verdades, por alguma falha de habilidade do pesquisador em transmitir a confiança necessária, ou ainda pela sua própria presença. Além desses fatores, embora se tenha tentado alcançar todas as possibilidades categóricas das táticas presentes nesse grupo de estudo, o resultado não deve ser generalizado, na medida em que os respondentes fazem parte do Corpo de Bombeiros Militar e Polícia Militar do Estado do Espírito Santo, que, apesar de serem dois órgãos de grande representatividade da segurança pública, não representam completamente esse setor, uma vez que tem-se também a Polícia Civil. Outra limitação refere-se à quantidade de entrevistados, pois a natureza da pesquisa qualitativa não permite uma grande quantidade amostral. Ademais, sabendo que o Brasil tem uma extensa dimensão geográfica e diferentes culturas regionais, pode ser que, em outros estados, os profissionais de segurança pública adotem táticas de manejo de fronteiras diferenciadas.

As táticas descobertas podem ser colocadas em prática pelos profissionais de segurança pública com a finalidade de alcançar o equilíbrio entre trabalho-lar. Já na perspectiva organizacional, podem-se desenvolver programas de equilíbrio trabalho-lar ao nível individual, levando em consideração a preferência por integração ou segmentação. Verifica-se que as organizações em geral, por meio do setor de recursos humanos, desenvolvem políticas gerais para equilibrar esse conflito, no entanto, elas poderiam categorizar e parametrizar os programas de equilíbrio trabalho-lar conforme o diagnóstico das necessidades apresentado pelo indivíduo ou por um grupo dentro da organização.

Outra implicação prática proveniente deste estudo diz respeito à possibilidade de replicação dessas táticas utilizadas pelos profissionais de segurança pública para os profissionais de outro setor público, como, por exemplo, o setor de saúde, em que os servidores trabalham em hospitais e prontos-socorros atendendo a emergências e, assim como os profissionais de segurança pública, lidam constantemente com demandas emergenciais de rotina e também extraordinárias, as quais induzem às 
violações de fronteiras entre os domínios trabalho-lar. Pode ainda ser praticada a replicação para outros grupos que tenham uma rotina de trabalho similar a dos profissionais de segurança pública, como, por exemplo, os engenheiros que trabalham por escala em indústrias e atendem às demandas emergenciais; os bombeiros profissionais civis que atuam em indústria, centros comerciais e portos; vigilantes e seguranças civis, com objetivo de diminuir o conflito trabalho-lar ou alcançar o equilíbrio entre esses domínios.

Sugerem-se quatro possibilidades de futuras pesquisas: (1) aplicação deste modelo a outros grupos, na tentativa de avaliar as similaridades e/ou buscar táticas novas e adicionais à teoria de base; (2) investigação da relação entre a interação dessas táticas e o nível de alcance do equilíbrio trabalho-lar ou redução dos conflitos; (3) realização de estudo empírico longitudinal para investigar se há mudanças de táticas pelo mesmo profissional, devido às mudanças ocorridas na rotina do trabalho ou do lar; e (4) investigação da simetria/assimetria dos fluxos no conflito/equilíbrio trabalho-lar, haja vista que os estudos referentes às táticas de manejo tratam as preferências individuais simplesmente como segmentadoras ou integradoras independentemente do fluxo (trabalho-lar ou lar-trabalho).

\section{Referências bibliográficas}

ALLARD, Karin; HAAS, Linda; HWANG, C. P. Family-supportive organizational culture and fathers' experiences of work-Family conflict in Sweden. Gender, Work \& Organization, v. 18, n. 2, p. 141-157, 2011.

Araujo, Bruno Felix von Borell de; TURETA, Cesar Augusto; Araujo, Diana Abreu von Borell de. How do working mothers negotiate the work-home interface? Journal of Managerial Psychology, v. 30, n. 5, p. 565-581, 2015.

Araujo, B. F. V. B.; RosA, A. R.; TURetA, C. Negociando as fronteiras entre trabalholar no contexto dos negócios internacionais: um estudo com mulheres expatriadas. In: ENCONTRO DA ANPAD, 36., 2012, Rio de Janeiro. Anais... Rio de Janeiro: ANPAD, 2012. Vol. 36.

Ashforth, Blake E.; Kreiner, Glen E.; Fugate, Mel. All in a day's work: boundaries and micro role transitions. Academy of Management review, v. 25, n. 3, p. 472-491, 2000.

ASHKANASY, Neal M.; HÄRTEL, Charmine E. J.; DAUS, Catherine S. Diversity and emotion: the new frontiers in organizational behavior research. Journal of Management, $v$. 28, n. 3, p. 307-338, 2002.

ASHKANASY, Neal M. et al. What are the management tools that come out of this. In: ASHKANASY, Neal M.; ZeRBE, Wilfred J.; ChARMINE, E. J. Managing emotions in the workplace. Armonk, NY: ME Sharpe, 2002. p. 285-296

BARDIN, Laurence. Análise de conteúdo. 3. ed. Lisboa: Edições 70, 2004. 
BEHAM, Barbara; DRoBNIC, Sonja. Satisfaction with work-family balance among German office workers. Journal of Managerial Psychology, v. 25, n. 6, p. 669-689, 2010.

BOYNE, George A. Explaining public service performance: does management matter?. Public Policy and Administration, v. 19, n. 4, p. 100-117, 2004.

BREWER, Gener A.; HUPE, P. Working both sides of the street: Bringing together policy and organizational perspectives on public service performance. In: 9th Public Management Research Association Conference, University of Arizona, October. Available at pmranet. org. 2007.

CARLSON, Dawn S.; KACMAR, K. Michele; StePinA, Lee P. An examination of two aspects of work-family conflict: time and identity. Women in management review, v. 10, n. 2, p. 17-25, 1995.

Chang, Artemis; McDonald, Paula; Burton, Pauline. Methodological choices in work-life balance research 1987 to 2006: a critical review. The International Journal of Human Resource Management, v. 21, n. 13, p. 2381-2413, 2010.

CLARK, Sue Campbell. Work/family border theory: a new theory of work/family balance. Human relations, v. 53, n. 6, p. 747-770, 2000.

EDWARDS, Jeffrey R.; RothBARD, Nancy P. Mechanisms linking work and family: clarifying the relationship between work and family constructs. Academy of Management Review, v. 25, n. 1, p. 178-199, 2000.

EISENhARDT, Kathleen M.; Graebner, Melissa E. Theory building from cases: opportunities and challenges. Academy of Management Journal, v. 50, n. 1, p. 25, 2007.

FORD, Michael T.; HEINEN, Beth A.; LANGKAMER, Krista L. Work and family satisfaction and conflict: a meta-analysis of cross-domain relations. Journal of Applied Psychology, v. 92, n. 1, p. 57, 2007.

GLASER, B.; StRAuss, Anselm. L. The discovery of grounded theory. In: GLASER, B. Strauss; STRAUSS, Anselm. L. The discovery of grounded theory: strategies for qualitative research. London: Weidenfeld and Nicolson, 1968.

GLYNN, Caroline; STEINBERG, Ingrid; MCCARTNEY, Claire. Work-life balance: the role of the manager. Horsham: Roffey Park Institute, 2002.

GoDoy, Arlida S. Introdução à pesquisa qualitativa e suas possibilidades. Revista de Administração de Empresas, v. 35, n. 2, p. 57-63, 1995.

HASLUCK, Chris et al. Work-life balance 2000: results from the Baseline Study. London: DFEE, 2001.

HILL, E. Wayne; DARLING, Carol Anderson; RaIMONDI, Nikki M. Understanding boundary-related stress in clergy families. Marriage \& Family Review, v. 35, n. 1-2, p. 147-166, 2003.

KATHERINE, A. Boundaries: where you end and I begin. New York: MJF Books, 1991. KREINER, Glen E. Consequences of work-home segmentation or integration: a person-environment fit perspective. Journal of Organizational Behavior, v. 27, n. 4, p. 485-507, 2006. 
Kreiner, Glen E.; Hollensbe, Elaine C.; Sheep, Mathew L. On the edge of identity: boundary dynamics at the interface of individual and organizational identities. Human Relations, v. 59, n. 10, p. 1315-1341, 2006.

Kreiner, Glen E.; Hollensbe, Elaine C.; SheEP, Mathew L. Balancing borders and bridges: negotiating the work-home interface via boundary work tactics. Academy of Management Journal, v. 52, n. 4, p. 704-730, 2009.

KULKA, Richard A. Interaction as person-environment fit. New Directions for Methodology of Behavioral Science, v. 55, p. 71, 1979.

LASCH, E. Achieving a balance. Ohio Certified Public Accounts Journal, v. 58, n. 1, p. 21-2, 1999.

MACDERMID, SHelley M. (RE) CONSIDERING CONFLICT BETWEen WORK AND FAMILY. IN E. E. KOSSEK \& S. J. LAMBERT (EDS.), WORK AND LIFE INTEGRATION: ORGANIZATIONAL, CULTURAL, AND INDIVIDUAL PERSPECTIVES: 19-40. MAHWAH, NJ: ERLBAUM. 2005.

MAINIERO, Lisa A.; SULLIVAN, Sherry E. Kaleidoscope careers: an alternate explanation for the "opt-out" revolution. The Academy of Management Executive, v. 19, n. 1, p. 106-123, 2005.

MAxWelL, Gillian A.; McDougall, Marilyn. Work-life balance: exploring the connections between levels of influence in the UK public sector. Public Management Review, v. 6, n. 3, p. 377-393, 2004.

NIPPERT-ENG, Christena E. Home and work: negotiating boundaries through everyday life. Chicago: University of Chicago Press, 1996.

Parasuraman, Saroj; Greenhaus, Jeffrey $\mathrm{H}$. Toward reducing some critical gaps in work-family research. Human Resource Management Review, v. 12, n. 3, p. 299312, 2002.

PoWELL, Gary N.; GREENHAUS, Jeffrey H. Sex, gender, and the work-to-family interface: exploring negative and positive interdependencies. Academy of Management Journal, v. 53, n. 3, p. 513-534, 2010.

RICE, Robert W.; Frone, Michael R.; MCFARLIN, Dean B. Work-nonwork conflict and the perceived quality of life. Journal of Organizational Behavior, v. 13, n. 2, p. 155168, 1992.

Rothbard, Nancy P.; PHILlIPS, Katherine W.; DuMAS, Tracy L. Managing multiple roles: work-family policies and individuals' desires for segmentation. Organization Science, v. 16, n. 3, p. 243-258, 2005.

Sundaramurthy, Chamu; Kreiner, Glen E. Governing by managing identity boundaries: the case of family businesses. Entrepreneurship Theory and Practice, v. 32, n. 3, p. 415-436, 2008.

Weiss, Howard M.; Cropanzano, Russell. Affective events theory: a theoretical discussion of the structure, causes and consequences of affective experiences at work. In B. M. Staw \& L. L. Cummings (Eds.), Research in organizational behavior. Greenwich, CT: JAI Press. Vol. 18: 1-74.1996.

YIN, R. Case study research: design and methods. 3 ed. Beverly Hills: Sage, 2003. 
Alexandre dos Santos Cerqueira

Doutorando do Programa de Pós-Graduação em Administração da Universidade Federal do Espírito Santo. Servidor Público Militar Estadual. Contato: alexandrecerqueira1971@yahoo.com.br

\section{Bruno Felix}

Doutorado em Administração pela Universidade Presbiteriana Mackenzie, com período de doutorado sanduíche em Psicologia Social na Universidad Complutense de Madrid (Espanha). Professor da Fundação Instituto Capixaba de Pesquisa em Contabilidade, Economia e Finanças (Fucape). Contato: bfelix@fucape.br

\section{Sabrina Zanotti Galon}

Mestre em Administração de Empresas pela Fucape Business School. Contato: sabrinazgalon@gmail.com

\section{Ariana Marchezi de Souza}

Doutoranda do Programa de Pós-Graduação em Administração da Universidade Federal do Espírito Santo. Contato: arianamds@yahoo.com.br 
